\title{
Jahrestagung 1978
}

Die Vereinigung hielt ihre Jahrestagung 1978 - die 30. seit ihrer Erneuerung 1949 - vom 4. bis 7. Oktober in Bonn ab. Zum zweiten Mal wählte sie damit den vorläufigen Sitz der Bundesorgane als Tagungsort, an dem zur gleichen Zeit vor 30 Jahren der Parlamentarische Rat an der Entstehung des Grundgesetzes arbeitete. Über 200 Mitglieder und ihre Damen besuchten die Tagung und die Veranstaltungen der Vereinigung.

Der Vorsitzende der Vereinigung, Klaus Stern (Köln), konnte zu den Referaten und Diskussionen in der Aula der Universität Bonn eine große Anzahl von Kollegen aus dem Ausland sowie die Schriftleiter der juristischen Fachpresse begrüßen. Die Diskussionsleitung lag in der Hand der weiteren Vorstandsmitglieder Thomas Oppermann für den ersten Beratungsgegenstand und Rupert Scholz für den zweiten Beratungsgegenstand.

Die Mitgliederversammlung gedachte der verstorbenen Kollegen Franz Mayer (Regensburg) und Friedrich Schack (Hamburg). Sie hatte sich neben Regularien im besonderen mit Satzungsfragen und der Einordnung der Allgemeinen Staatslehre, der Verfassungsgeschichte der Neuzeit und des Kirchenrechts in die Wahlfachgruppen der juristischen Ausbildungs- und Prüfungsordnungen zu befassen. Zehn neue Mitglieder wurden aufgenommen und vorgestellt. Der amtierende Vorstand, Klaus Stern (Köln), Thomas Oppermann (Tübingen) und Rupert Scholz (München), wurde in geheimer Wahl wiedergewählt. Er kooptierte Dieter Wilke (Berlin) zur Durchführung der Jahrestagung 1979 in Berlin vom 3. bis 6. Oktober 1979.

Die Arbeitssitzungen der Vereinigung wurden von festlichen Veranstaltungen umrahmt: Am ersten Abend durch ein Konzert in der Schloßkirche der Universität Bonn, bei dem das Collegium Musicum unter der Leitung von Emil Platen musizierte, und einen Empfang des Rektors der Rheinischen Friedrich-Wilhelms-Universität Bonn, Magnifizenz Aloys Heupel, in den Festräumen des Kurfürstlichen Schlosses. Am zweiten Abend empfing Herr Bundespräsident Walter Scheel die Mitglieder und ihre Damen in der Villa Hammerschmidt. Den Ausklang der Arbeitstagung bildete der festliche Ball in der Redoute in Bad Godesberg. Am Samstag fand der traditionelle Ausflug in die Umgebung statt: zur romanischen Kirche 
Schwarzrheindorf und zum Altenberger Dom. In beiden Kultstätten war unser Kollege Ulrich Scheuner ein ebenso kunstverständiger wie geschichtskundiger Führer.

Besonderen Dank schuldet die Vereinigung den Mitgliedern der gastgebenden Fakultät, vor allem dem kooptierten Vorstandsmitglied, Herrn Fritz Ossenbühl, seiner Frau und ihren Mitarbeiterinnen und Mitarbeitern für die Mühe und Umsicht bei der Vorbereitung und der reibungslosen Organisation der Tagung.

Die nachstehend abgedruckten Referate wurden jeweils am Vormittag des 5. und 6. Oktober gehalten. Ihnen folgte am Nachmittag die vollständig wiedergegebene Diskussion. 